\title{
Literatura hebrea y literatura castellana
}

\author{
Fernando díaz Esteban *
}

\section{LITERATURA Y CONVERSOS}

La literatura, además de una posible fuente de noticias, es en sí misma un dato histórico. Representa, no solamente el caudal de las ideas de un momento dado a las que se quiere expresar de una manera que suponga un goce estético, sino también, cuando hay influencias de unas literaturas sobre otras, las afiniclades espirituales y estéticas en un tiempo concreto entre dos universos aparentemente separados.

Los entrecruces entre la literatura hebrea y la castellana van más allá de la historia de la literatura y muestran como dato histórico que los hispanohebreos o judíos de España no vivían aislados ni eran ajenos a la vida espiritual de sus compatriotas cristianos, en la que participaban por medio de la literatura de éstos. Las obras castellanas de los judíos circulaban con plena normalidad y se aceptaba lo que de innovación pudieran representar cuando ofrecían novedades.

Empleamos el término «judío» de una manera lata, es decir, incluimos en él a los conversos y a los descendientes de conversos. Quizás haya que descartar a estos últimos en futuros estudios, salvo en los casos en que vuelven al judaísmo de sus abuelos. He expuesto en otro momento ${ }^{1}$ que cuando se publicó el Edicto de Expulsión, los judíos que se quisieron quedar en España no tuvieron más que declararse dispuestos a recibir las aguas del bautismo, hacerse "conversos», como de forma creciente desde el siglo xIV venía ocurriendo en la Península. En términos generales, "converso" ha pasado a tener el significado restringido, por antonomasia,

Universidad Complutense.

Conferencia de clausura del curso de verano de la Universidad de Castilla-La Mancha, "Cultura hispano-judía y sefardí», I. Toledo, 6 septiembre 1991, sin publicación. 
de judío que se ha hecho cristiano. Pero hay conversos y conversos: los hay sinceros, los hay indiferentes y los hay simuladores por el miedo o el interés material. Y luego está el problema de los hijos de los conversos y aún el de los que tuvieron un abuelo converso.

Para los judios piadosos el converso es un 'anús, un forzado, pues muy a duras penas admiten que haya conversiones sinceras. Moisés Orfali $^{2}$ ha reunido la jurisprudencia judía sobre los conversos, los 'anusim, para los cuales los jurisperitos dejan siempre una puerta entreabierta para que vuelvan al judaísmo. Esta postura contrasta con la anécdota exhumada por Marcel Bataillon del fraile portugués Pantaleāo de Aveiro, quien recorriendo Palestina entre 1563 y 1565 encontró ciertos judíos que le confiesan que eran buenos cristianos, pero que al ver quemar a sus padres por la Inquisición se habían venido a Tierra Santa y vuelto al judaísmo ${ }^{3}$. Es la misma queja que mucho antes había lanzado Antón de Montoro ante la persecución de los conversos de Córdoba: «imás les valiera ser judíos!». Se ha novelado mucho sobre la supuesta inseguridad de los conversos y su repercusión en la literatura, sin reparar en que tal inseguridad era general y no una exclusiva judía. En los siglos xIV y xV, los de mayor influencia política de los conversos, vemos que el rey don Pedro I muere a manos de su hermano bastardo, luego Enrique II; que el todopoderoso valido de Juan II, don Álvaro de Luna termina en el cadalso; que el rey don Enrique IV recibe la afrenta de un simulacro de destronamiento; que don Pedro López de Ayala y Fernán Pérez de Guzmán estuvieron en la cárcel; que los Reyes Católicos mandaron desmochar los torreones urbanos de las familias nobles revoltosas, etc., etc. En tiempos así, los menos favorecidos, como los judíos, y los verdaderamente desfavorecidos, como los pobres labradores, no podían estar muy seguros, aunque como siempre, la gente acaba habituándose a la inseguridad. ¿No sentiría un sobresalto cualquier español de los siglos XVI a XIX si se enteraba que la Inquisición le estaba rondando, por muy inocente que se sintiera?

Durante los reinados de Juan II y Enrique IV de Castilla, y mucho antes, los conversos son públicos y notorios. Como la conversión era un acto solemne y público, todo el mundo sabía quién y desde cuándo era converso. Los altos puestos políticos, económicos y eclesiásticos que alcanzan los conversos en la sociedad se explican porque la conversión era

2 Orfal Levi, Moisés, Los conversos españoles en la literatura rabínica. Problemas jurídicos y opiniones legales durante los siglos XII-XVI. Salamanca, Universidad Pontificia, 1982.

3 BATAILLON, Marcel, «El protosionismo hispanoportugués», Nueva Revista de Filología Hispánica, n. ${ }^{\circ}$ XXIV, 1975, págs. 125-141. 
un hecho socialmente aceptado. Algunos de estos conversos, que paradójicamente fueron personalidades ilustres dentro del judaísmo, dieron prueba de un celo cristiano peligroso para la paz de cristianos y judíos. Escriben obras en hebreo, en latín o en castellano en las que se ataca al judaísmo con argumentos sacados de sus conocimientos de las fuentes judías. Es el caso de Abner de Burgos, convertido en Alfonso de Valladolid, de Salomón Leví, convertido en Pablo de Santa María, de Josúa ha-Lorquí, convertido en Jerónimo de Santa $\mathrm{Fe}$, etc., que siguen el camino que había iniciado Moisés Sefardí de Huesca, convertido en Pedro Alfonso.

Frente a estos conversos celosos, la abundancia y persistencia de conversos fingidos es un fenómeno típico del judaísmo hispánico. Se dio en tiempos del rey godo Sisebuto, en los que los judíos fueron puestos en el brete de hacerse cristianos o salir de la Hispania visigoda. Muchos optaron por fingir la conversión en espera de tiempos mejores, lo que, en efecto, al cabo de algún tiempo ocurrió; los que habían salido del país pudieron volver, pero para los que se habían convertido hubo dificultades para que se aceptase su vuelta al judaísmo. Sin embargo, este precedente de tiempos visigodos no creo que fuera tenido en cuenta en la España musulmana cuando los almohades, nuevos Sisebutos, exigen la conversión al Islam o la expulsión. Muchísimos prefirieron simular la islamización y el propio Maimónides dio ejemplo simulando y justificando la falsa conversión en espera de tiempos mejores. En otro lugar ha señalado ${ }^{4}$ que esta actitud permisiva de Maimónides, y de los hispanohebreos en general, se origina en la España musulmana, de donde luego pasó a la cristiana, y tiene una clara influencia islámica. En efecto, Mahoma permite la simulación de una conversión si con ello se salva la vida, sin más obligación que la vuelta al Islam cuando haya pasado el peligro. Esta actitud mahometana contrasta con la del cristianismo, que en este punto es heredero del antiguo judaísmo, conservado por el judaísmo centroeuropeo, que exige el martirio antes que la pública abjuración de la fe. Avalados por el dictamen de Maimónides, cuando en la España cristiana se producen persecuciones, muchos judíos practican la simulación de la conversión, y debió de ser ampliamente seguida en el momento de la Expulsión o Destierro de 1492.

Es comprensible que la comprobación de la abundancia de falsas conversiones levantara en la sociedad cristiana fuertes sospechas de hipo-

¿Por qué los hispano-judios fueron más tolerantes con las conversiones simuladas? Conferencia en la Amistad Judeo-Cristiana de Barcelona, 18 mayo 1978, sin publicar, aludida en è Prólogo de Orfali, pág. 10. 
cresía religiosa ante cualquier converso. Esta sospecha generalizada, y frecuentemente injusta, acaba dando lugar a la llamada Inquisición Española, después de la Expulsión o Destierro de 1492, considerada como una medida cautelar, y finalmente, a los estatutos de limpieza de sangre. De este modo, la permisividad en la simulación de la conversión de los judíos españoles iniciada en la España musulmana, se volvió contra ellos mismos.

Para el hijo o el nieto del converso el problema de la conversión resultaba, desde su punto de vista personal, algo lejano; había vivido desde niño como cristiano y había recibido una formación, frecuentemente universitaria, también cristiana. $Y$ sin embargo, la sospecha también le podía alcanzar, sobre todo si la Inquisición descubría entre sus ascendientes algún falso converso. Es natural, por tanto, que el hijo o nieto de conversos intente disimular ${ }^{5}$ su calidad de tal; no tiene la razón publicitaria del converso, pues él ha nacido ya cristiano. Sin embargo, el término converso se emplea, lo empleamos, incorrectamente llamando converso a quien solamente es hijo o nieto de un converso y decimos «de familia de conversos" aunque en su familia sólo un lejano abuelo lo fue. Muchas de las grandes personalidades de nuestro Renacimiento y Siglo de Oro fueron de este tipo de «conversos» impropios. Es el caso de Fray Luis de León, Santa Teresa, Luis Vives, Juan del Encina, ... por otra parte, ejemplos de devoción cristiana.

El fenómeno del criptojudaísmo, tan habitual entre los judíos españoles como hemos visto, tiene una variante en los judaizantes que descienden de algún converso y vuelven al judaísmo de sus antepasados de modo secreto, los marranos, teniendo que salir fuera de España para poder manifestar públicamente su judaísmo. El marranismo se produce por proximidad familiar o amistosa con alguien que secretamente sabe despertar una especie de entusiasmo o de nostalgia por pertenecer al pueblo judío ${ }^{6}$. Otras veces es la reacción ante la quema en auto de fe de algún familiar, que hace que se despierte una reacción de dignidad y de solidaridad con los suyos.

5 El humanista extremeño Sánchez de ias Brozas, el Brocense, en el proceso que le abre la Inquisición por mostrarse más racionalista que respetuoso con las tradiciones devotas, declara no recordar el nombre de sus abuelos, lo que se ha tomado como indicio de que no eran labradores, sino conversos.

¿ El caso más notable fue el de David Rubení, que logra que Diogo Pires vuelva al judaísmo con el nombre de Salomón Molcho; he contribuido a la abundante bibliografía con «Problemas de Ienguaje en David Rubenim, en Proceedings of the 3rd International Congress for the Study of Sephardi and Oriental Jewry. Jerusalén, julio 1988, en prensa. 
Hay otro tipo de converso, que es el que yo llamaría «el converso mítico". Es un converso que se ha inventado Américo Castro y han seguido sus discípulos, yendo más allá de los prudentes pasos de Marcel Bataillon. Se ha acuñado el concepto de converso como "casta", cuando en realidad es un grupo humano poroso, absorbible por los demás y penetrante entre todos los demás grupos, desde la nobleza a los labradores, desde la curia al ejército. Este "converso mítico» ha sido adornado, además, con las plumas de la inteligencia, el conocimiento de la propia valía y el desprecio hacia las otras «castas» que tienen su superioridad exclusivamente por herencia, no por las propias obras. Siente una gran amargura y su desprecio se manifiesta en los ataques al clero y a las instituciones nobiliarias, e incluso a todos los españoles en general. La creación quimérica de este "converso mítico" yo creo que se debe a un error de apreciación del inconformismo de la generalidad de los intelectuales, sean de cualquier raza, tiempo y religión, considerándolo, al enfocar solamente a los judíos, como un distintivo propio del converso. $\mathrm{Na}$ turalmente que se encuentran algunos de esos signos entre ellos, pero también se encuentran en el Canciller Ayala o en Quevedo o en la larga lista de la poesía de protesta medieval ${ }^{7}$. Lo cual no obsta para que, como en el caso del Padre de las Casas, la inestabilidad psicológica se agravara con una cierta obsesión, si es que la tuvo, por sus antepasados conversos.

\section{MOAXAJAS HISPANOHEBREAS}

Las moaxajas, como es sabido, son poesías estróficas inventadas en la España musulmana de la época del emirato independiente, cuya estrofa final terminaba en unos versos o frases en lengua romance ${ }^{8}$. Desde el punto de vista histórico, la moaxaja y su jarcha representan la incorporación de la población autóctona a la literatura de los árabes invasores

\footnotetext{
7 La influencia de Américo Castro llega a Rodríguez Puertolas, Julio, La poesía de protesta en la Edad Media castellana. Madrid, Gredos, 1968, pág. 51, atribuyendo al converso unos rasgos de insatisfacción que están manifiestos en todos los autores que ha seleccionado, sean cristianos viejos o nuevos. La obsesión por amoldar a los conversos a lo que Américo Castro dice de ellos obnubila a Rodríguez Puértolas hasta el punto de no darse cuenta que su propia selección de obras de protesta es el mayor alegato contra la tipificación conversa.

8 La existencia de tal romance ha sido puesta de relieve por GALMES, A., "Algunas normas para la interpretación de las jarchas romances», en F. Corriente y A. Sáenz-Badilios (eds.), Poesía estrófica. Actas del l Congreso Internacional sobre Poesia Estrófica Árabe y Hebrea y sus Paralelos Romances. Madrid, Facultad Filología Universidad Complutense/Instituto Cooperación Mundo Árabe, 1991, págs. 105-120.
} 
llevando a ella dos elementos propios: el juego de las estrofas y la sensibilidad amorosa femenina conocida después como "cántigas de amigo». Hay que rendir tributo de admiración a la cultura arábigo-musulmana por su capacidad de absorción de las diversas culturas de los países donde se iba asentando, arabizando e islamizando los elementos que le convenían, como es el caso del estrofismo hebreo y cristiano-visigótico según creo haber demostrado en sendos congresos de Exeter y Madrid ${ }^{9}$. La última parte de la estrofa final, la jarcha, podía estar también en el ascendente árabe vulgar que se estaba hablando en Al-Andalus junto con el romance ya en declive. Los judíos imitan prontamente en hebreo la técnica y la temática de las moaxajas árabes, y junto a los elementos romances e hispanoárabes introducen la lengua hebrea en esa estrofa final, que, a veces, siguiendo la costumbre de los poetas árabes, toman de otra moaxaja anterior, sea árabe o hebrea. Pero hay, al menos, un caso en que el poeta hebreo no toma de la canción mozárabe o de otro árabe la jarcha, sino que la compone íntegramente él mismo. Se convierte así en el primer poeta en español ${ }^{10}$ de nombre conocido: el judío Yehudah ha-Leví (m. 1141), compositor de una cuarteta romance-mozárabe al final de una moaxaja hebrea ${ }^{11}$. Se trata de la conocida moaxaja hebrea en honor de Cidiello, cortesano de Alfonso VI, al que los judíos de Guadalaja esperan recibir (entre 1091 y 1095) de visita. Tras un «Responded» (RŚPND), la comunidad había de cantar ${ }^{12}$.

\author{
Meu cidiello vénid $=$ MW SDYLH BNYD \\ con bona-l-bišāra $=K N$ BWNH 'LBYŠRH \\ com raio de sol éxid $=K M R^{\prime} Y W$ DŠWL 'ŠY \\ en Wad-al-haŷära $=$ 'N W'D 'LÂG'RH.
}

9 "La poesía latina visigoda y el nacimiento de la moaxaja», en A. Jones y R. Hitchcock (eds.), Studies on the Muwaăš̌ša'n and the Kharja IProceedings of the Exeter International CoIloquium], Reading, Itaca Press/Fac. Oriental Studies U. Oxford 1991, págs. 136-148 y «La poesía estrófica hebrea de época bizantina en citas bíblicas", en CoRRIENTE y SÁENZ-BADILlos, Poesia Estrófica, págs. 93-104.

${ }_{10}$ Sería prematuro llamarlo castellano y quizá tardío romance mozárabe; Y. ha-Leví por haber atravesado Castilla desde Tudela y realizar visitas a Toledo es llamado también «el castellano".

11 Lo puse de manifiesto en «la aportación judía a la literatura castellana», en Las tres culturas en la corona de Castilla y los sefardies. Actas de las Jornadas sefardies y del Seminario de las tres culturas. Valladolid, Junta de Castilla y León, 1990, págs. 14-29.

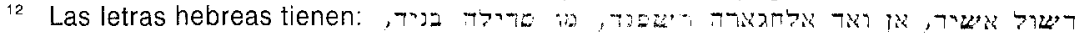

según Millás

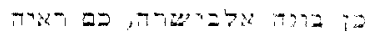


Los dos arabismos que emplea Yehudah ha-Leví no son ajenos al castellano: uno, al-bišāra "la buena noticia», dio «albricias»; el otro, wad alhayāra «río de las piedras» es el nombre que sigue llevando la ciudad de Guadalajara.

Así, pues, la primera composición en Castilla de autor conocido es esta cuarteta de versos de seis sílabas, rimando primero con tercero y segundo con cuarto, que está al final de una poesía hebrea. La lengua es romance, la escritura hebrea y la ortografía de la transcripción es árabe. En tan pequeño documento podemos simbolizar la situación vital de los judíos españoles, atraídos por el mundo cristiano y por el musulmán, y cómo ya desde sus comienzos, intervienen en las primeras fases de la literatura castellana.

Los moaxajas de los poetas hispanohebreos son numerosas y en ellas, cuando las hay, las jarchas romances suelen estar mucho mejor conservadas que en sus paralelos árabes, llegados en copias modernas y por quienes no entendían el romance ${ }^{13}$. El estudio de las jarchas romances adelantó el origen de la lírica castellana al menos a dos siglos antes que la épica de «Mío Cid».

En el momento de producirse la invasión musulmana, el latín hablado por la población se estaba convirtiendo en romance. La invasión cortó el desarrollo regular y uniforme por toda la península al dividirla en zonas poco comunicadas entre sí y separadas políticamente. En la España musulmana el dialecto llamado mozárabe conservó algunos de los rasgos del habla del momento de la invasión, mientras que en los extremos del norte, en Galicia y Cataluña se inició un desarrollo propio, aunque tienen muchos rasgos comunes por ese común origen y por ir quedando en la retaguardia de la Reconquista. Más adelante, Castilla evolucionó desde el gallego-leonés a unas formas lingüísticas innovadoras, que se ensayarán en la poesía épica mientras que en la poesía lírica se siguió empleando la lengua que se consideraba la más propia para la lírica, el gallego, que por su carácter relativamente arcaico estaba más próximo al romance mozárabe de la España musulmana. En este remoto origen de la poesía lírica en Castilla, todavía no plenamente en castellano, se entrecruzan, como hemos visto en Yehudah ha-Leví la literatura hispanohebrea y la castellana.

13 Cf. Galmes, pág. 107; Jones, A., Romance Kharjas in Andalusian Arabic Muwašša'n Poetry. A Palaeographical Analysis. Oxford 1988, ha hecho un notable esfuerzo para reducir los inseguros datos de los manuscritos árabes a ordenador. 


\section{BIBLIAS ROMANCEADAS}

La importancia de la Biblia en todas las literaturas europeas ha sido y continúa siendo enorme. No se trata ahora de resaltar su papel en la literatura española, a la que se incorpora por la traducción, por el comentario, por la alusión y por la inspiración para componer nuevas obras ${ }^{14}$, sino de poner de manifiesto una peculiaridad española: la traducción desde finales del siglo XII o mediados del XIII de la Biblia hebrea directamente del hebreo al castellano con la colaboración de judíos. J. Llamas ${ }^{15}$ ha puesto de manifiesto que hay manuscritos bíblicos castellanos que tienen partes traducidas de la versión latina y partes del original hebreo. Las traducciones castellanas hechas para los judíos no tienen, como es natural, más que los libros del canon judío del Antiguo Testamento, mientras que entre los cristianos se traduce los libros deuterocanónicos y el Nuevo Testamento. Conviene recordar que hasta el Concilio de Trento no había graves inconvenientes para utilizar las traducciones directas del hebreo a la lengua vulgar; en cuanto a los judíos, tampoco tenían impedimento para hacer, utilizar y poseer dichas traducciones.

Para mejor entender el texto bíblico, latino o hebreo, tanto los cristianos como los judíos tienen una larga tradición de comentaristas. A lo largo de la Edad media ha habido dos comentaristas judíos que, traducidos al latín o conocidos directamente en hebreo por judíos conversos, han influido en los comentaristas cristianos. La última de las biblias romanceadas, la llamada Biblia de Alba intenta combinar los comentarios e interpretaciones de cristianos y judíos; su autor, Moisés Arragel, como en casos de uno y dos siglos anteriores, es un judío que traduce para patrones cristianos y tiene que hacer esas combinaciones. En la Biblia Políglota Complutense, Alfonso de Zamora, judío converso, hace uso de David Qimhí, cuya exégesis o Exposión a los 59 Salmos de David tradujo al castellano, y de Abraham Ibn Ezra. Benito Arias Montano, a quien Felipe II encargó la "Biblia Regia» o «Biblia Políglota de Amberes», tradujo parte en castellano y parte en latín, a Quimhí ${ }^{16}$ y en Fray Luis de León

\footnotetext{
1 En «La Biblia en la literatura española: Formas de incorporación», El Olivo, n. ${ }^{\circ} \mathrm{XII} / 28$, 1988, págs. 175-196, expuse mi opinión de cómo los autores españoles habian utilizado el texto bíblico.

5 LLAmAS, J., Biblia medieval romanceada judío-cristiana. Madrid, C.S.I.C, 1950 (I), 1955 (II).

${ }_{16} \mathrm{KIMCHI}$, David, Comentario sobre Isaías, parte sobre Jeremias y parte sobre Malachia, traducido en romance y parte en latín, manuscrito en El Escorial, según Rodríguez de Castro.
} 
en sus interpretaciones bíblicas, sobre todo en el Cantar de los Cantares expresamente alude a los "maestros hebreos" y a Abraham Ibn Ezra.

Vemos, pues, que desde el siglo XIII (o finales del XII) hay un entrecruce entre lo hebreo y lo castellano en lo que respecta a las versiones castellanas de la Biblia, que no siempre se hacian del latín. No hay unos rasgos especiales en el castellano de estas traducciones judeo-castellanas; su arcaísmo lingüístico es el natural del momento en que se hacen; su agarrotamiento o literalidad es el corriente en la Edad Media. La famosa "Biblia de Ferrara", hecha en 1553 por judíos españoles desterrados residentes en Italia y allí impresa es un caso excepcional y diferente a las Biblias romanceadas. Las biblias romanceadas intentaban hacer inteligible y poner en buen castellano lo que hay en el original hebreo. La Biblia de Ferrara, por el contrario, traduce palabra por palabra el texto hebreo y en el mismo orden en que en él se encuentran; no se trata aquí de una fase arcaica o de poca habilidad del traductor, sino de un propósito firme que responde a unos supuestos ideológicos: tener delante de los ojos en palabras castellanas el texto hebreo. Sus editores, Gerónimo Vargas y Duarte Pinel imprimen unos ejemplares con una Dedicatoria al duque Hércules II de Este y otros con una Dedicatoria a doña Gracia Naçí por Yom Tob Attias; Rodríguez de Castro fue el primero en reconocer que se trataba del mismo libro con dødicatorias diferentes ${ }^{17}$. En el Prólogo los autores sienten el orgullo de su lengua española, como los demás marranos en general, y dicen: "como en todas las Provincias de Europa o de las más, la lengua española es la más copiosa y tenida en mayor precio, así procuré que esta nuestra Biblia, por ser en lengua castellana, fuese la más llegada a la verdad hebraica." Tras afirmar que se han consultado todas las traducciones y los manuscritos hebreos antiguos que se pudieron hallar, a modo de excusa se dice que «fue forzado de seguir el lenguaje que los antiguos hebreos españoles usaron». Esta expresión ha llevado a algunos a pensar que los judíos españoles tenían una especie de dialecto propio, del que derivaría el actualmente llamado sefardí, pero la realidad es que tal dialecto no existió entre los judíos de la Península, aunque como es natural, a la hora de traducir ciertas frases hechas o conceptos la interpretación rabínica surgiría casi automáticamente, cuando

17 Batalllon, Marcel, “¿Melancolía renacentista o melancolía judía?», en su Varia lección de clásicos españoles. Madrid, Gredos, 1966, págs. 39-54, subraya el hecho de que cuando los expulsos empiezan a publicar, comienzan con un libro de Oraciones (1552) y sigue luego la Biblia de Ferrara (1553) y los Salmos en español, la Consolaãm as tribulaçóes de lsrael de Samuel Usque, «mezcla de Biblia y novela pastoril», reimprimen (1554) la Visión deleitable de Alfonso de la Torre, combinación de San Isidoro y Maimónides, con la elegíacas Coplas de Jorge Manrique. 
no la propia palabra hebrea. Probablemente el Prólogo lo que quiere decir es que se pretende seguir un lenguaje relativamente arcaico, como el de las biblias romanceadas, sin advertir que lo que resultaba arcaico a mediados del siglo xvi, era la lengua normal en el tiempo en que se traducía. Hay, pues, un deseo expreso en la Biblia de Ferrara de continuar una tradición, pero al mismo tiempo se nota que la ruptura entre la sociedad española cristiana y la judía que se había consumado con la Expulsión de 1492 tiene su reflejo en esta disociación de fines de la Biblia de Ferrera respecto de la tradición romanceada anterior. Una segunda edición revisada en Amsterdam en 1630 se hará para que los cristianos puedan utilizarla, suavizando esa «palabra por palabra» que no se correspondía con el deseo de la fácil comprensión de las biblias romanceadas.

Una de las características de los judíos convertidos al cristianismo suele ser el empleo abundante de las citas bíblicas, a lo que estaban acostumbrados en su anterior etapa judía. Es el caso, por ejemplo, de Juan el Viejo, nacido a mediados del siglo xIV. En su Memorial de los Misterios de Cristo escrito ${ }^{18}$ en 1416, y en especial en su Declaración del salmo LXXII se muestra versado en la Biblia (de hecho, en el Salmo 72 encontramos un verdadero centón de citas bíblicas) y en opinión de Amador (pág. 431) «no deja lugar a dudas haber sido uno de los más doctos rabíes de su tiempo»; la familiaridad con las argumentaciones talmúdicas no le impide tener un lenguaje castellano que, también según Amador (pág. 43) «iguala en sencillez y pureza al usado por otros escritores del mismo tiempo».

Rodríguez de Castro y Amador de los Ríos han llamado la atención sobre un libro publicado en Lyon en 1543 que es una especie de resumen de la Biblia, una Historia Sagrada, que aunque en el prólogo se dedica al "cristiano lector», su autor es un judío de origen español, Francisco de Frellon, que en opinión de Amador (pág. 491) «no había conocido su autor ias innovaciones de Garcilaso» pues emplea los versos tradicionales y no el italianizante de once sílabas, por lo que se debió de escribir algunos años antes de su impresión. El libro se titula Retratos o tablas de las historias del Testamento Viejo y llegó a ser utilizado como catecismo por los judíos. He traído a colación esta obra porque representa, frente a las numerosas enemistades políticas, una extravagante convivencia espiritual: obra castellana de un judío expulsado de Castilla, impresa en Francia, de donde los judíos llevaban expulsados más de un siglo, que es un resumen

18 En él declara que ya es un viejo, relata su conversión y expone el diferente concepto que tienen del Mesías los cristianos, moros y judíos. 
del Antiguo Testamento, con un prólogo para el cristiano lector y usada como libro de enseñanza por los judíos hispanoparlantes.

Entre los marranos o judíos procedentes de conversos de la Península se siguió la costumbre de traduccion castellanos de la Biblia, especialmente de los Salmos, con comentarios y a la moda de la spalabra por palabra» ${ }^{19}$, sin contar la versión en verso de López Laguna ${ }^{20}$. Y del Cantar de los Cantares, incluso con la traducción de su paráfrasis caldea del Targum ${ }^{21}$.

Antes que la Biblia, se imprimió por los judíos expulsados su libro de oraciones. Corresponde a los judíos de origen hispano-portugués las primeras traducciones de los oracionales judíos a una lengua europea. Según H. P. Salomón, un manuscrito portugués de hacia 1550 podría ser el primer intento ${ }^{22}$, mientras que la primera obra impresa es el oracional con oraciones de todo el año de Yom Tob Attias en 1552 y en ese mismo año en Venecia Isaac Cavallero imprimía en hebreo y en español las oraciones del sábado; tanto Attias como Cavallero utilizan la moda del «palabra por palabra» ${ }^{23}$. De finales del siglo xvı son otros oracionales en castellano impresos en Maguncia, anteriores a los de Amsterdam ${ }^{24}$. El rito seguido en Amsterdam se impriió varias veces a lo largo del siglo XVII ${ }^{25}$,

19 Psalterio de David. En Hebrayco dicho Thehylim, trasladado con toda fidelidad verbo de verbo del Hebrayco. Y repartido como se deve leer en cada dia del mes segun uso de los Antiguos. Amsterdam 1650. De Jacob Judá León Hebreo, llamado Templo, es la traducción con comentario y anotaciones La Albanãs de Santidad. Traducción de los Psalmos de David por la misma phrasis y palabras del Hebrayco, por JEHUDAH, Jahacob. Amsterdam 1671. De un converso portugués vuelto propagandista italiano es el libro en portugués La consolación cristiana de un desdichado judio, exposición del libro de los Salmos por BAPTISTA DE ESTE, Juan. Lisboa 1616.

20 Titulada Espejo fiel de vidas.

21 Cantares y levares, che dicho Schlomo el Propheta, Re de Israel con Spiritu de prophesia, delante Senior de todo el mundo, Jehova (traducción española del Targum por R. Mosen Ben Samuel Laniado. Venecia 1619, con letras hebreas con numerosas reediciones en Amsterdam 1644, 1664, 1683 y en 1701 con el título Paraphrasis Caldayca, En los Cantares de Selomoh, con el Texto Hebrayco y Ladino tradusida en Lengua Española. Amsterdam 5461=1701).

22 SAlomon, H. P., "The "Last Trial" in Portuguese», en Studi sull'ebraismo italiano in memoria de Cecil Roth. Roma 1974, págs. 159-183: se trata de un manuscrito iluminado escrito en Italia.

23 Salomon, H. P., "The "Last trial"...".

24 Orden de Roshasanah y Kipur trasladado en español. Estampado por Yahacob Israel. Maguntia 20 Adar 5343=1583; por ser esta edición la más antigua, las siguientes llevan la indicación "nuevamente enmendado»: Orden de Roshasanah y Kipur, trasladado en español y de nuevo enmendado y añadido al Selihot. Estampado por Yahacob Israel. Maguntia 20 Adar $5344=1584$.

25 Orden de las Oraciones impreso en Amsterdam por: Nicolas de Ravesteyn, 1648; Daniel Vaez y Joseph Athias, 1677; Isaac de Cordova, 1706; Moshe Méndez Cotinho, 1706; Samuel Texeira Tartas, 1738; Salomon Proops, 1716. 
rezos ordinarios ${ }^{26}$, o los rezos del mes ${ }^{27}$, o de las fiestas principales ${ }^{28}$. Las ediciones y reediciones de los rezos son numerosas: en 1630 los rezos de los cinco ayunos («tahaniot») del rito sefardí; en 1631 los de la semana, llamados «mahamadot»; en 1663 los del mes y dos fiestas ${ }^{29}$. Las enmiendas eran continuas y la abundancia de ediciones tiene su paralelo en el lado cristiano, donde los misales y libros litúrgicos para uso del clero producidos en la Península y en Amberes por la imprenta de Plantino ${ }^{30}$, eran distribuidos y vendidos a cientos en la Península y en América.

\section{OBRAS PARALELAS}

Los autores que escriben en hebreo y en castellano es natural que repitan ideas o recursos estilísticos en una y otra literatura. Los conversos que habian recibido su formación intelecual en hebreo y en hebreo habían escrito, después de su conversión al cristianismo suelen escribir en latín (Pedro Alfonso) o en castellano (Alfonso de Valladolid y don Pablo de Santa María). A partir del siglo XVI, después de la Expulsión, los marranos o criptojudíos que se marchaban a los Países Bajos, Italia y Turquía siguen escribiendo en castellano (y en portugués) como lo hacían en la Península, aunque a veces prueban sus fuerzas en hebreo. En las generaciones posteriores se da más la familiaridad con el hebreo. A título de ejemplo recordemos del siglo XVII a Joseph Peuso de la Vega, famoso como dramaturgo en castellano, que escribió en hebreo un drama alegórico titulado 'Ásire ha-tiqwah «Prisioneros de la esperanza» (Amsterdam 1673); del siglo xvIII, a David Franco Mendes que escribe en hebreo un libro misceláneo de poesías Kinnor David (Amsterdam 1731-39) que luego contiene una traducción al hebreo de una octava del Imperio de Dios en la Harmonía del Mundo de Miguel de Barrios.

En la Edad Media, sin embargo, no es frecuente que un judío sea literato en ambas lenguas. Casi la única excepción es don Santo de Ca-

${ }^{26}$ Orden de 10 que se deve leer cada dia y noche. Impreso por David de Castro Tartas, 1666; o Orden de bendiciones y las ocaziones en que se deven dezir. Amsterdam 1687.

${ }_{27}$ Orden de oraciones de mes Arreo sin boltar de una a otra parte. Amsterdam 1618.

28 Orden de Ros Asanah y Kipur. Traduzido en Español y de nuevo emmendado y añadido el Keter Malchut y otras cosas, estampado en Amsterdam por David Pardo y Salom Ben Yosseph, 1630, reimpreso por Daniel Pereira y Mosseh Moreno Henriques, Amsterdam 5423=1643.

${ }_{29}$ Libro de Oraciones de mez y la Orden de Hanukah y Purim, con un añadido de calendario para varios años.

30 Puesto de manifiesto a lo largo de las intervenciones del Simposio Internacional sobre Cristóbal Plantino, Ed. H. Tromp y P. Peira. Madrid, U. Complutense, F. Filología, 1990, págs. 14-16 y passim. 
rrión, Rabí Šem Tob Árdutil, traductor, poeta y prosista en hebreo, además de autor de los Proverbios morales en castellano. Como creo haber demostrado ya hace tiempo ${ }^{31}$, en su macama hebrea «El Debate del Cálamo y las Tijeras" y en sus Proverbios Morales castellanos coinciden varios temas, además de la afición sentenciosa. Cabe destacar los siguientes ${ }^{32}$ :

1. la figura del astroso pero sabio:

"/Y salió la pluma a la plaza del pueblo y encontró allí a un hombre pobre / sabio en toda sabiduría./»;

2. el elogio del libro:

«/..Y aquel que te ga pluma y tinta / más que todos los compañeros le baste./2);

3. el elogio de la pluma:

«/tú conocías que con toda mi fuerza / te había servido con entereza de corazón y limpieza de manos, / con el sudor de mis palmas / como esclavo azotado y cautivo/s

4. la utilización de las tijeras para recortar las letras:

"/cógete un estilo de hierro / que te ayudará más que diez plumas! / $Y$ hazte renglones y palabras como los grabados de los sellos recortados./",

5. el que cada cosa se utilice para lo que vale:

«/cada uno se aplique a su utensilio; / todo utensilio cuando trabaje sea para lo que Dios lo hizo./»

Estos temas también están presentes en sus «Proverbios Morales»o Consejos y documentos al rey don Pedro / castellanos:

1. 'e omr' much' entendido / por ser vergonçoso es por torpe tenido / e llamado astroso"

2. «Por ende tal amigo / non ha commo el libro; para los sabios digo / que con torpes non libro»

\footnotetext{
31 «El Debate del Cálamo y las Tijeras", Revista de la Universidad de Madrid (Homenaje a Menéndez Pidal I), vol. XVIII, n. ${ }^{\circ} 69,1969$, págs. 61-102.

${ }^{32}$ El texto hebreo en SCHIRMANN, H., Ha-Širah ha-ibrit bi-Sěfarad u-ba-Probans, $3{ }^{\text {a }}$ ed.,

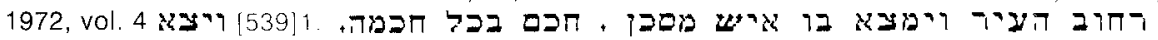


3. «Por end' un serviçial / de que mucho me preçio quiero, tant' es leal, / contar el su bolliçio [actividad]»

$\cdots$

4. «un astroso cuydaba / y por mostrar que era sotil, yo le enviaba / escripto de tisera»

5. «ca una cosa pide / la sal, otra la pez».

No sabemos si su obra hebrea en prosa rimada es anterior a los versos castellanos, pero en todo caso parece razonable pensar que los temas comunes eran materiales tomados de la tradición de las macamas hebreas continuadores de las macamas árabes, temas que él habría ido recogiendo para su «Debate» en hebreo. Amador de los Río ${ }^{33}$ dice tajantemente de los Proverbios/Consejo y Documentos que revelan que el autor había hecho sus primeros estudios en los libros sagrados de la Biblia y que no se podía desasir de los escritores propiamente rabínicos, dados a toda clase de amplificaciones. La importancia, un tanto desenfocada, que dio Américo Castro ${ }^{34}$ a don Santo no hace más que poner de relieve la significación de este entrecruce entre la literatura hebrea y la castellana como simbiosis cultural, que produce la primera obra en verso de tono sapiencial de la literatura castellana.

R. Šělomoh ha-Leví, convertido en Don Pablo de Santa María el 21 de julio de 1390, escribe en castellano una historia universal basada en la Biblia, titulada Las Edades Trobadas, en la que, según Amador (pág. 342), «no se había apagado en él aquella imaginación oriental... que enriquecían las descripciones poéticas, aunque la forma era algo ruda e incorrecta», y continúa Amador (pág. 343) afirmando que cuando traduce sigue el orden hebraico y que para traducir "sea la luz, y fue la luz» hay que tener delante el texto hebreo ${ }^{35}$. Al final puso una relación de los reyes que había habido en España desde Noé, según una fabulosa tradición muy antigua que consideraba a Tubal el primer poblador de España. Su me-

\footnotetext{
33 AMAdOR de los Rios, José, Estudios históricos, politicos y literarios sobre los judios de España. Madrid 1884, págs. 327.

${ }^{34}$ La realidad histórica de España. México 1954. De resultas de la réplica de SÁNCHEZ ALBornoz, Claudio, España, un enigma histórico. Buenos Aires 1956, Castro tuvo que suprimir en su 2. ${ }^{a}$ ed., 1962, el capítulo independiente que había dedicado a Don Santo de Carrión.

35 La traducción habitual del latín es "hágase la luz, y la luz fue hecha».
} 
trificación, como antes en don Santo de Carrión, opina Amador (pág. 353) que es probablemente de origen hebraico.

Confieso humildemente que nunca he entendido bien qué quería decir Amador de los Ríos con ésta y otras frases similares que repite a lo largo de sus Estudios. En mi trabajo sobre don Santo de Carrión expuse que el rabino rimaba el castellano según la métrica hebrea y por eso algunos autores castellanos posteriores, aunque le admiran, se lamentan de que sus versos están mal rimados, desde la óptica de la métrica castellana, naturalmente; Amador lo que parece indicar es que el ritmo o la largura de los versos se asemejaban a los hebreos. Al hablar de Rabí Moseh, cirujano de Enrique III, que escribe en 1405 un poema para celebrar el nacimiento del príncipe Juan (II) Amador comenta: «respira cierto orientalismo, hijo sin duda de la poesía arábiga y de la poesía hebraica, que tanta influencia tenían en la castellana... los versos de maestría mayor nos parecen de mayor mérito que los octosílabos, lo cual puede atribuirse a que se hallaba aquella metrificación más puesta en uso y a que guardaba más analogía que otra alguna que la empleada por los escritores rabínicos en todos sus poemas» (pág. 421).

También encuentra (pág. 374) en Alvar García de Santa María, hermano de don Pablo de Santa María y converso como él, cuando escribe en castellano las crónicas de los reyes Enrique III, Juan II y de don Álvaro de Luna, que: como literato tiene buen orden, lenguaje pintoresco, estilo natural.. pero notándose con frecuencia que sus primeros estudios eran debidos a la literatura rabínica por los hebraísmos que emplea.

Podemos aceptar que el gusto por lo sentencioso, la forma de utilizar las citas bíblicas, ciertos temas literarios traídos de la literatura hebrea medieval y, muy poco probablemente, la preferencia por ciertas medidas del verso pueden ser el resultado de la incorporación a la literatura castellana de personas que durante su niñez y adolescencia habían recibido fundamentalmente una educación literaria hebrea.

Sin embargo, cuando llega a España el movimiento prerrenacentista, es el hijo de don Pablo de Santa María, Alfonso de Cartagena (m. 1456), uno de los introductores de esa corriente, que con el tiempo permitirá la existencia de judíos renacentistas y la incorporación de la literatura hebrea, más adelante, a ese movimiento. En otro lugar ${ }^{36}$ he hecho notar cómo Alfonso de Cartagena se separa totalmente de la literatura en hebreo

36 «Alfonso de Cartagena, literato y político", en Actas del Congreso Internacional Judíos y Conversos en la Historia. Ribadavia, octubre 1991, en prensa. 
y se vuelve hacia los nuevos aires latinizantes, imperantes en la corte de Juan II, estilo que su hermano Gonzalo de Santa María también empleó. Más adelante, tanto judíos como conversos que escriban en español seguirán las corrientes renacentistas y las siguientes culteranas y conceptistas del Barroco.

\section{AUTORES-TRADUCTORES DE SI MISMOS}

Un autor se traduce a sí mismo cuando piensa que en la lengua original en la que ha escrito su obra, ésta no va a tener eficacia para lo que fue concebida. Es el caso en tiempos helenísticos de Flavio Josefo, que escribe en arameo pero acaba traduciéndose a sí mismo al griego. El converso don Alfonso de Cartagena (m. 1456) escribe algunas de sus obras en latín de temas histórico-literarios y jurídico-políticos ajenos a la tradición hebrea pero de interés para el reino de Castilla, por lo que para su mayor difusión también él mismo traduce una parte de tales obras al castellano a ruego de los demás.

En los autores en hebreo, normalmente es en las obras de carácter polémico donde la necesidad de traducción se manifiesta de modo imperativo: la versión original hebrea está destinada a los judíos, mientras que la traducción romance está pensada para un público cristiano. Alfonso de Valladolid es el ejemplo más conocido. Su nombre judío fue Abner de Burgos y tomó el de Alfonso de Valladolid a partir de su conversión. Nació en el ultimo tercio del siglo XIII y murió a mediados del XIV y ha sido objeto de un profundo estudio por Carlos Sainz de la Maza ${ }^{37}$, quien propone (vol. l, pág. 248) que «escribirá en hebreo y se autotraducirá al castellano, quizá para... judíos desconocedores de la lengua bíblica, o... para que conozcan sus ideas algunos de sus nuevos correligionarios [= cristianos], entre los que podría contarse algún protector poderoso no muy ducho en latines". El arsenal polémico de Abner de Burgos/Alfonso de Valladolid es importante y tuvo una gran repercusión polémica tanto entre los judíos como entre los cristianos. En castellano traducido del hebreo se conserva parcialmente el Libro de las batallas de Dios (c. 1320), y completo el Mostrador de Justicia (c. 1330), en el que se emplea el diálogo entre el Mostrador, es decir, el que enseña, el maestro, evidente hebraismo, pues es traducción literal de "que muestra» equivalente a maestro, y el

37 Sáinz de la MAZa Vicioso, Carlos N., Alfonso de Valladolid: Edición y estudio del manuscrito Lat. 6423 de la Biblioteca Apostólica Vaticana, tesis doctoral, Universidad Complutense, Departamento de Filología Española, 11. Madrid 1989, 2 vols. 
rebelde judío; ya otro converso, Mošeh Sefardí de Huesca/Pedro Alfonso Había utilizado la forma dialogada en su Dialogus Petri et Moysii, o disputa entre su yo judío y su nuevo yo cristiano. El diálogo polémico tiene en la literatura judía el famoso Kuzari de Yehudah ha-Leví (¿1070-1141), originariamente escrito en árabe, en donde el diálogo o disputa se mantiene entre cuatro representantes de las respectivas religiones. También en doble versión, Alfonso de Valladolid tiene Torre de Fortaleza (c. 1330) y Libro del zelo de Dios (c. 1335) y otras más, no siempre seguras de él o de que las escribiera en doble versión, obras que se relacionan con su denuncia de la costumbre litúrgica judía de maldecir a los herejes (los cristianos, según Alfonso), y con sus ideas sobre el fatalismo astrológico. El conjunto de sus obras en castellano permite afirmar a Sainz de la Maza (I, pág. 248) que reflejan «la fuerza y variedad de recursos del castellano post-alfonsí para tratar incluso los temas más especializados en el ámbito clerical teológico y filosófico» y «el nuevo interés por lo didáctico y lo doctrinal que rompe, en la transición de los siglos XIII al XIV, la hegemonía de la historia, la astrología y la narrativa de la época alfonsí».

Este entrecruce de las dos literaturas representado por Alfonso de Valladolid, al tiempo que nos señala un momento de la polémica antijudía en lengua castellana, nos indica la incorporación de los conversos a ella aportando sus conocimientos del pensamiento judío escrito en hebreo. Y supone, además, una adaptación flexible de la prosa castellana a temas antes expuestos solamente en latín.

Dentro de la polémica antijudía, Josúa ha-Lorquí, convertido en 1414 en Jerónimo de Santa Fe escribe en latín Hebraeomastix o "Azote de los Hebreos" del que tradujo él mismo al castellano el primer tomo dedicado a convencer a los judíos. La abundante producción polémica de los conversos celosos de su nueva fe, tanto si escribían en hebreo como en castellano o latín, produjo a su vez entre los judíos una abundante producción de obras en hebreo en defensa del judaísmo, viniendo así a establecerse un entrecruce antagónico, pero tratando los mismos temas.

\section{TRADUCCIONES AL CASTELLANO}

Las traducciones al castellano de obras hebreas, dejando aparte la Biblia, ya vista, son tardías en general. La fase previa es la de la traducción del hebreo al latín y del latín a las lenguas vulgares. En más de un caso, el texto hebreo era a su vez una traducción de un original árabe escrito por un hispanojudío. Los judíos de los países cristianos que no dominan bien el árabe necesitaban tales traducciones. Es el caso del citado Kuzarí, de Yehudah ha-Leví, el de Los Deberes de los Corazones de Bahyà Ibn 
Pacuda, y de diversas obras gramaticales, científicas y filosóficas. En la literatura amena nos podemos encontrar con que el original árabe llega al castellano por la doble vía de la traducción hebrea y de la retraducción latina. Es el conocido caso del Calila y Dimna, del que existe en castellano dos versiones: una, directa del árabe; otra, traducida de la versión latina de Juan de Capua hecha sobre la versión hebrea de Rabí Joel de otro original árabe.

Aparte de las traducciones científicas del árabe al castellano hechas por los judíos de los tiempos de Alfonso $X$ el Sabio, se tradujo de otras lenguas peninsulares, como en 1350 un «Poema sobre el ajedrez y contra los juegos» de R. Mošeh de Zaragua, en ¿hebreo/catalán? traducido al castellano por autor Anónimo, seguramente judío o converso, en opinión de Rodríguez de Castro; la traducción castellana está en dísticos de versos de 12/14 sílabas. Ya es sabido la preocupación que para los moralistas judíos (y para los cristianos) suponía el vicio del juego de dados y cartas, mientras que era considerado honesto el ajedrez.

Las traducciones directas del hebreo son tardías, como el Kuzarí, de 1663, por Jacob Abendana ${ }^{38}$ y los Deberes de los Corazones, de Ibn Pacuda por David Pardo ${ }^{39}$ en 1610, y luego al portugués por Isaac $\mathrm{Abaz}^{40}$ en 1670 . Recordemos que ambas obras pertenecen a las originariamente escritas en árabe y luego pasadas al hebreo, como así mismo la famosa Guía de Perplejos de Maimónides. La obra despertó el interés de los cristianos muy pronto, de ahí el que ya en la primera mitad del siglo $x \vee$ se tradujera al castellano por encargo del maestre de la Orden de Santiago, don Gómez Suárez de Figueroa; el traductor fue el converso Maestro Pedro de Toledo ${ }^{41}$. Esta primera versión castellana de la Guía de Perplejos / Moreh něbukim, se terminó en Sevilla en 1432, conservando, lo mismo que había hecho Alfonso de Valladolid (Moreh=Mostrador), el hebraísmo del título, Mostrador y enseñador de los turbados, pues está

se Cuzary / Libro / De grande sciencia... / Discursos... entre el Rey Cuzar y un singular Sabio I de Ysrael... / Fue compuesto este libro en Lengua Arabiga / por el Doctissimo / R. Yeuda Levita I Y traduzido en la Lengua Santa por el / famoso Traductor / R. Yeuda Aben Tibon / En el año de 4927 a la Criacion del mundo / Y agora nuevamente traduzido del Ebrayco en Español, y comentado / Por el Hacham / R. Jaacob Abendana / Con estilo facil y grave. Amsterdam $5423=1663$.

${ }_{39}$ Obligación de los corazones, traduzido de hebraico en lengua española, por David Pardo. S.1. 5370 .

40 Obriganza dos corazoens, tirado da hebraica a lingua portuguesa per Samuel Fillo de Isaac Abaz. S.I. 5430.

${ }^{41}$ El manuscrito ha sido publicado por A. J. Escudero Ríos en edición facsímil, MAIMONIDES, Guía de Perplejos. Madrid 1990, mientras que M. Lazar había publicado el texto en 1989. 
basada en la versión hebrea del original árabe; Pedro de Toledo intenta justificar sus dudas y manipulaciones del texto con la dificultad de la materia.

También de Maimónides son dos traducciones, una hecha por David de Lara del célebre De Regimine sanitatis, escrita en árabe en 1198 y luego traducida al hebreo en 1244 , de donde se traduce al castellano ${ }^{42}$ y la otra la Měnorat ha-ma'or, de Isaac Aboab, traducida por Jacob Hages ${ }^{43}$ conserva hebraismos técnicos y en general su lenguaje castellano parece estar perdiendo la pureza, como un anuncio del lunfardo que luego será el sefardí o judesmo. Por ejemplo, además de los tecnicismos hebreos «helek (heleq), perek (pereq), berahot (berrakot), abot (Padres)", usa expresiones como "consolar a los lutosos (a los de luto), aviziar los malos...». En el prólogo «Al letor» hace austeras consideraciones sobre la muerte y la conveniencia de cumplir la Ley que Dios dio a Moisés, y continúa:

«quiso el S.B. por mereçimientos de mis pasados darme fuerza para sacar a la luz un comento en lenguaje ebraico sobre las misnaiot que intitulé Arbol de la Vida y allándome para imprimir dicha obra aquí, en Liorne, paresiome por benefisio común traduzir este libro que te ofresco intitulado Menorat amahor q. quiere dezir Almenara de la luz añadiendo algo de mi poca capasidad para más inteligensia de los que no son muy corrientes en las declaraciones de nuestros sabios y en el lenguaje bulgar por lo poco corrientes en el ebraico... Procuró el Autor de traher las sentencias de nuestros sabios a propósito de su doctrina cada coza en su lugar donde podrá el devoto letor empl[e]ar alguna ora del dia en leer algunos capitulos desta obra considerando el estilo con que nuestros sabios dizen sus documentos, y advierta el curiozo letor que la tradusión fue muy al pie de la letra, por lo que no podrá el lenguaje ser muy agradable, pues no es posible traduzir de una lengua en otra y ser el lenguaje muy político sin añadir, o quitar y en cosas de nuestros Sabios no se puede disminuir ni añadir por ser todo sentençias con que te suplico admitas mi trabajo reçibiendo la Obra no según el estilo sino según su fecunda doctrina que dedico a nombre del S. D. de Israel pidiendo de su Divina $M$. accepte mi trabajo y ser grato en sus ojos (sic, hebraismo) que este es el premio que pretendo... dándome vida para meldar en su ley y me libre de ofenderle como dixo el rey Dauid inclina mi coraçon a tus

42 Tratado de Moralidad y de Regimiento de la vida de Rabbenu Mose de Egypto, por David Lara. Hamburgo 1622.

${ }_{43}$ Utilizo la edición Almenara de la luz. Tratado de mucho provecho para beneficio del alma compuesto en lengua ebraica por el gran sabio Yshac Aboab. Traducido en lengua vulgar para beneficio comun por el Haham lahacob Hages. Amsterdam 1708. Rodríguez de Castro utiliza otra: Almenara de la luz. Tratado compuesto en lengua hebriaca por Ishac Aboab Halav Asalom, y traducido en lengua vulgar por Jahaco Hages. Liorna 1656. 
mandamientos y no a intereses mundanos sean por mi voluntad dicho de mi boca y pensamientos de mi coraçón delante de ti. A mi fuerte y $\mathrm{mi}$ redemidor Amen Tu humilde afisionado el Haham lahacob Hages».

Obras que habían sido compuestas recientemente en hebreo y no tenían por tanto la veneración de clásicas, también se tradujeron al castellano.

La Historia de persecuciones titulada La Vara de Juda había comenzado a ser compuesta en Sevilla por Yehudah Verga (Lisboa 1485) antes de la Expulsión y se terminó por Salomón Verga (1460-1554) ya fuera de España en 1507, con retoques de su hijo Yosef Verga, nacido en Turquía (m. 1559). Se tradujo ${ }^{44}$ al español en 1640 por un enigmático M. De L. Este es también el caso de David Nieto, cuyo Fuego Legal se tradujo al castellano y publicó en Londres ${ }^{45}$. Como de Maimónides pasó un Re'šit Hokmah que en realidad era de Elías de Vida, traducido por David de Lara con el título de Tratado del temor divino ${ }^{46}$.

Los temas legales también se traducían como es el caso de Árbaàh Turim/Los Cuatro Órdenes, de Jacob ben Aser (Colonia c. 1270-Toledo 1340), publicada la traducción en $1609{ }^{47}$. Una antigua costumbre de la poesía hebrea recitada en las sinagogas era la de las poesías que trataban los preceptos judíos; estas poesías litúrgicas recibían el nombre de 'azhărot, admoniciones. Una continuación en el siglo XVIII de esta costumbre entie los judíos españoles fue traducida del hebreo al español ${ }^{48}$.

También, aunque no se trata de relación directa con la literatura hebrea, por su interés judío, los marranos tradujeron al español obras no escritas en hebreo. Los traductores generalmente dan cuenta de cómo y porqué han hecho la traducción. Este es el caso de Josef Semah Arias que traduce el Contra Appionem de Flavio Josefo ${ }^{49}$. La dedicatoria está

44 Vara de Ivda compuesto por el rab Selomoh hijo de Verga en Hebrayco y traduzido en lengoa (sic) española por M. de L. Amsterdam 1640; hay otra edición de 5504=1744.

${ }_{45}$ Fuego Legal, compuesto en ydioma hebraico y traducido en romance Anonimo. [Es la obra Éš dat, «Fuego de ley», de R. David Nieto Ben Pinhas]. Londres 1715.

${ }_{46}$ Tratado del Temor divino, extracio del libro llamado Ressit hohma. Traducción española de R. David Ben Izcha Cohen de Lara dei tratado de Maimonides sobre el Amor de Dios. Amsterdam 1633.

47 Libro del mantenimiento de la alma, traduzido del hebraico al Spagnol por Moseh Altharas. Venecia 1609.

48 Memoria de los 613 preceptos de la S. Ley y Siete de Sabios. Traducido del hebrayco de un Canto compuesto por el H. H. R. Selomoh Sasportas. Amsterdam $5487=1727$.

49 Respuesta de Josepho Contra Apion Alexandrino. Traduzida por el Capitan Joseph Semah Arias. Dedicada al Doctissimo Señor Yshac Orobio de Castro Catedratico de Medicina en la Universidad de Sevilla. Y en la de Tolosa, Professor, Medico y Consejero, del Rey de Francia, Impresso en Amsterdam en Casa de David Tartas Año 1687. 
escrita en un estilo que claramente muestra la moda conceptista y en ella afirma que la traducción se hace «... contra las censuras de los Apiones desta era..." y continúa: “... parece que la fatalidad o providencia predestinó esta obra (que la malicia de unos y el descuydo de otros no comunicó en Idioma vulgar) para este siglo en que concurriesse yo, como estatua de Josepho, por lo material y V.M. como Alma de esta estatua, por el entendimiento...», "... En el nombre tuve la dicha de ser Josepho, en la Nación la Gloria de ser Hebreo, en lo militar la honra de ser Capitán: mas faltandome las letras de aquel insigne Sabio, para resucitar, apelé a las de V.M. para que levantando figura del más Sabio, acertasse con el más Docto que inspirando aliento de vida en mi Estatura material, ella cobrase alientos para otros progresos, y recomendación contra la censura... mas con la protección de V.M. hará apetecible lectura lo que fuera enfadosa lección». En el prólogo dice al «Amigo y Sabio lector: Si ere de mi Nación, no me parece que yerro en darte el título de Amigo, pues de razón deves serlo de quien saca a la luz en lengua Española este libro... $Y$ si fueres de otra Nación, siendo sabio, creo que te dignarás de nuestra amistad, conociendo nuestra Antigüedad, nuestras Grandes y Heroycas acciones, y la fidelidad y respecto (sic) que en todos los tiempos tuvimos y tenemos a los Príncipes y Repúblicas, a quien somos sujetos...». La aprobación religiosa de la obra la hizo en portugués Ishac Abuab De Fonseca, y comete el mismo error que el propio Arias cuando dice en el elogio del libro: «O qual foy traduzido de Grego em Latin, e em as demais linguas eceyto na Espanhola, porque ésta por emulaçāo da Religiāo, procura enterrar algumas cousas que encóntrem a sua... Se deven dar apludidos Elogios a o Capitāo Joseph Semah Arias... que conduzió sua traduçā o a Estampa, para recreaçāo dos tementes do Senhor. Amsterdam 2 de lunho 5447 [1687].» El entusiasmo del traductor y de su censor estaba un tanto exagerado, pues al parecer no conocían que la versión de Arias no era la primera, sino la tercera de las castellanas de Flavio Josefo ${ }^{50}$. La primera versión castellana está traducida de la versión latina editara por Rufino, patriarca de Aquilea ${ }^{51}$ y se publicó en Sevilla en 1492 por Alonso de Palencia, cronista de los Reyes Católicos ${ }^{52}$. La segunda traducción castellana se debe a Juan Martín Cordero, que empieza pu-

50 Rodríguez de Castro ya hizo notar que le había precedido Alfonso de Palencia y al mismo tiempo observó que la traducción de Aria era un compendio en algunas partes, lo que muestra con trozos del texto griego, de Palencia y de Arias.

51 Venecia 1486; Basilea 1524.

52 Los Siete libros de la Guerra Judaica y los dos Contra Appion... en latin por Ruffino Patriarca de Aquileya y en romance castellano por Alfonso de Palencia. El "Prólogo"se había publicado en 1491. 
blicando en Sevilla en 1532, luego en Amberes en 1554; en Madrid, 1557; en Perpiñán, 1608 y desde entonces hasta 1985 ha tenido al menos ocho reediciones de sus traducciones de Flavio Josefo. La publicación en 1687 de la traducción de Joseph Semah Arias puede deberse a que la última edición anterior, de Juan Martín Cordero, se había realizado treinta años antes, en Madrid, en 1657. Aunque los marranos que vivían en Flandes tenían conocimiento de la literatura española contemporánea, cuyas modas seguían, muestran a veces un cierto desconocimiento de algunas obras. Este es el caso del marrano Francisco de Cáceres, que publicó en Francfort en 1623 y en Amsterdam en 1663 la Visión deleitable traducida del italiano ${ }^{53}$, tomándola por obra original, cuando en realidad, como ya mostró Rodríguez de Castro en 1781, el italiano no había hecho más que traducir del castellano al italiano dando como obra propia la que era de Alfonso de la Torre, publicada en Burgos 1485, Tolouse 1489, Sevilla en 1526 y 38 y en Ferrara por los propios judíos en 1554. Otro marrano del mismo apellido, Joseph de Cáceres, tiene una hermosa traducción castellana de una obra francesa que va glosando el relato bíblico de la Creación con frecuentes alusiones de la mitología grecorromana. Se trata de Los Siete dias de la semana sobre la criacion del mundo ${ }^{54}$, escrita en verso, la traducción es en prosa, en un castellano excelente y con mucho gusto. En la dedicatoria a Ishac Tyrado nos dice: «... traduxe este libro de lenguaje y verso Francés en romance y prosa castellana; compúsolo Guillaume de Salusto, Señor de Bartas ${ }^{55}$, a quien toda la Francia llama Príncipe de los Poetas Franceses... muestra el autor la grandeza de su yngenio y su mucha lección, ansi en letras diuinas como humanas: es digno que los doctos lo lean, los buenos yngenios la celebren, los curiosos la estimen, los deuotos la agradezcan, y todos la admiren. Bien es verdad que la traducción le abrá quitado la autoridad que tenía en el propio verso, porque demás de muchas razones que ay para esto, ay otra que es general, que toda cosa semejante, es inferior a la propia... Mas si se considera cómo yo sólo he tomado este entretenimiento por facilitar a los Españoles la ynteligencia de tan buen poema creo que alcanzaré perdón de las muchas faltas." Joseph de Cáceres luego se muestra sibilino para dar a entender que ha cambiado algo el texto, probablemente

\footnotetext{
53 Vision deleytable y sumario de todas las Sciencias traducida de italiano en Español por Francisco de Caceres. Amsterdam 1663.

54 Por Josepho de Cáceres. Amstradama, Alberto Boumeester, $5372=1612$, portada con escudo de orla y cestillo. La segunda portada tiene escudo con recuadro y lises y la fecha de $5373=1613$, más la dedicatoria "Dirixida al muy Illustre Señor lacob Tyrado Parnas de la Nacion Portuguesa, que reside en esta muy noble y opulenta villa de Amstradama».

55 Conocido por Bartasio o Du Bartas.
} 
para descristianizarlo o judaizarlo: «... en no le aber traducido puntualmente: las causas y razones que a ello me an mouido, reservo para los curiosos que de mi las quisiean saber..." En el «Advertimiento al lector» justifica las erratas que aparecen porque «Considere el lector que estamos fuera de España y que los impresores estan muy remotos que la impresion Castellana, y que yo tambien soy nobicio en semejantes cosas...».

Ya muy lejos de la literatura hebrea, pero no de los judíos, están los Diálogos de Amor de León Hebreo, que como es sabido era hijo del protegido de los Reyes Católicos don Isaac Abarbanel, quien a pesar de todo prefirió el marcharse fuera de España. La primera traducción castellana se debe a un judío de origen peninsular. La Philografia, está escrita en latín e inmediatamente fue traducida al italiano. La traducción española de 1568 es de Guedella lahia, en Venecia, mientras que la del Inca Garcilaso es de 1590 y la de Montesa de $1602{ }^{56}$.

\section{TRADUCCIONES AL HEBREO}

La literatura hebrea tiene un cierto hermetismo frente a las obras no hebreas, que contrasta con su permanente apertura a las técnicas, los gustos y los temas de las otras literaturas con las que convive en el tiempo y en el espacio. Absorbe ideas, técnicas y gustos, pero transformando todo y dirigiéndolo para que resulte un producto conforme con la tradición hebrea. Son escasas, por ello, las traducciones completas, pero si abundan las adaptaciones y las copias descaradas. La literatura árabe ha sido la que ha contribuido con una mayor aportación de traducciones al hebreo. Las obras filosóficas, místicas, científicas o gramaticales de autores judíos que entran aquí en consideración. Quitando éstas, se traduce o adapta algunas poesías anacreónticas, por Yehudah ha-Leví, por ejemplo, las macamas de al-Hamadani y de al-Maàrrí, por ha-Harizí, la alegoría filosófica de Avicena Hay ben Yaqt'an/EI Viviente hijo de/ Vigilante por Abraham ibn Ezra. La cuentística oriental pasada al árabe fue también traducida y adoptada al hebreo. Las literaturas medievales europeas no ofrecían para los judíos ni el interés ni la afinidad que lo que se encontraba en árabe. Pero durante el Renacimiento y después, las literaturas europeas

56 Los Diálogos de Amor de Mestre Leon Abarbanel, Jehudah Ben R. Izchaq Abarbanel, traducción castellana de Guedeila lahia. Venecia 1568; Garcilaso Inca de la Vega. Madrid 1590; Philographia universal de todo el mundo o Diálogos de León Hebreo, Micer Carlo Montesa. Zaragoza 1602. La traducción francesa Philosophie d'amour de Champenois. Lyon 1595, es, por tanto, posterior a las dos primeras castellanas. 
reemplazan a los árabes tanto en las ciencias como en lo artístico; sin embargo la literatura hebrea tarda en reaccionar ante este nuevo estímulo con traducciones, quizás porque tras la Expulsión y hasta la Ha'skalah i llustración predomina la literatura jurídica y apologética y la disputa teológica representada por Menasseh ben Israel (Manoel Dias Soeiro) ${ }^{57}$, Spinoza, Orobio de Castro y Juan de Prado, en lengua peninsular ${ }^{58}$. Por ello es más notable el que en el momento siguiente a la Expulsión se traduzca al hebreo la obra de López de Gomara Historia General de las Indias... desde el descubrimiento... hasta $1551 \ldots$ Con la conquista de México... (Zaragoza 1553), sobre la conquista de América. La traducción la terminó Yosef ha Kohen en 1557 y aunque no llegó a imprimirse, circuló en manuscritos, de modo que el hecho del descubrimiento y conquista de América entra así pronto en la literatura hebrea mediante esta traducción directa hecha por Yosef ha-Kohén, un descendiente de expulsos.

\section{LITERATURA CASTELLANA DE LOS JUDIOOS}

La aportación de los escritores castellanos de origen judío se caracteriza por su impulso renovador o por la instauración de novedades. Después de la Expulsión, la literatura castellana de los judíos fuera de España tiene una vía muerta cuando en el Imperio Turco se generaliza el imprimir libros en castellano pero con letras hebreas, vía muerta que acaba desembocando en la llamada literatura sefardí, sin contacto ya y sin influencia con la literatura de la Península. La vía viva es la producción de los judíos en letras latinas. Escriben y publican en castellano en los Países Bajos, en Italia y en Francia. Son libros que pueden ser leídos e incluso impresos en la Península y que se entroncan directamente con la producción literaria peninsular ${ }^{59}$. Responden a las corrientes conceptistas y culteranas en la retórica, al teatro español de Lope de Vega y Calderón de la Barca y a los temas bíblicos, mitológicos ${ }^{60}$ y de costumbres ${ }^{61}$ ha-

57 Menasseh Ben ISRael, Esperanza de /srael, introducción, edición y notas de H. Mechoulan y G. Nahon. Madrid, Hiperión, 1987

58 El ambiente está documentado en Revah, I. S., Spinoza et le Dr. Juan de Prado. París 1959.

59 La equívoca devoción española de los judíos está estudiada por Mechoulan, Henry, Hispanidad y judaísmo en tiempos de Espinoza. Estudio y edición anotada de "La Certeza del Camino» de Pereyra, Abraham. Amsterdam 1666. Salamanca, Univ. de Salamanca, 1987.

oo Sánchez Fernández, J. L., Poemas mitológicos de Miguel de Barrios. Córdoba, Inst. Historia de Andalucía, 1981 (con un estudio de su métrica y retórica).

61 Entique Gómez, Antonio, El siglo pitagórico y Vida de don Gregorio Guadaña. Edition critique avec introduction et notes par CHARLES AMIEL. Paris 1977 (poesías y una novela picaresca). 
bituales en los autores españoles del Barroco, aunque algunos asuntos, como la novedad del mundo de la Bolsa, nunca se había tratado ${ }^{62}$. Solamente los puntos religiosos conflictivos o la orientación que se dé a los temas comunes separa a los cristianos de los judíos nuevos o viejos. Los Macabeos es un tema común, pero el largo poema épico de Miguel de Silveyra El Macabeo (Nápoles 1638, Madrid 1731) está compuesto desde una perspectiva más judía que cristiana; su imitación, el poema heroico Sansón Nazareno (Ruan 1656) de Antonio Enríquez Gómez se ajusta al relato bíblico, aceptable para los cristianos, pero sin referencias explícitas cristianas. Tanto Silveyra como Enríquez hacen uso, sin embargo, de la mitología grecorromana para adornar el relato. Entre la neutralidad, el disimulo o el ataque, los conversos retornados al judaísmo llenan de preocupaciones judías una buena parte de la literatura española del Siglo de Oro.

62 EnRique Gómez J. A., La Bolsa en José de la Vega "Confusión de Confusiones», Amsterdam 1688. Madrid 1980. 